\title{
UN RECORRIDO POR LOS DERECHOS COLECTIVOS EN LA JURISPRUDENCIA ARGENTINA
}

\author{
Nohora Elena Pardo Posada ${ }^{1}$ \\ Universidad Libre-Bogotá
}

Fecha de entrega: 23.07.2014

Fecha de evaluación: 02.09.2014

RESUMEN

Fecha de aprobación: 15.09.2014

La jurisprudencia argentina así como su legislación reconoce la tutela judicial de los derechos de incidencia colectiva por mandato de la reforma constitucional del año de 1994 art 43 y siguientes, normas que son interpretadas por la Corte Suprema de la Nación en sus pronunciamientos judiciales, a partir de ellos se ha establecido el alcance de los artículos constitucionales mencionados, como la legitimación en materia colectiva. Se presenta el tema investigado dividido en cuatro etapas que comienzan con el fallo Toninas en el año de 1983 hasta la demanda interpuesta por la unión de usuarios y consumidores contra telefónica comunicaciones personales S.A, donde se verifican los efectos comunes para los sujetos afectados, propios de la protección colectiva.

\section{ABSTRACT}

The Argentina case law and legislation recognizes the legal protection of collective rights mandated by the constitutional reform of 1994, s 43,44 and 46, which have been developed by the Supreme Court of the Nation in its judicial pronouncements, since they have established the extent of constitutional articles mentioned, such as standing in collective matter.

PALABRAS CLAVES: derechos colectivos, amparo, legitimación.

Key words: collective rights, protection, legitimacy

\section{INTRODUCCIÓN}

\footnotetext{
${ }^{1}$ Abogada de la Universidad Libre. Magister en Derechos Administrativo y Especialista en Derecho Administrativo de la misma Universidad, especialista en docencia Universitaria Universidad La Gran Colombia. Maestrando en derecho procesal de la Universidad del Rosario Argentina. Docente de la Universidad Libre - Bogotá. Miembro del grupo de investigaciones de derecho público del centro de investigaciones socio jurídicas de la Universidad Libre. Artículo avance proyecto de investigación "El mecanismo de revisión eventual de acciones populares" Correo Electrónico: nohora09@gmail.com REVISTA VIA INVENIENDI ET IUDICANDI, Vol. 9, No. 1 
Hablar de derechos colectivos en el mundo globalizado, es cambiar los presupuestos iniciales de la legitimación en materia procesal dirigida a la protección de los derechos subjetivos, se acude en la actualidad y por imposición de la posmodernidad (Chaumed; 2000) al amparo de derechos que no están atribuidos a la persona particularmente considerada sino a la colectividad o al grupo y en este transición las legislaciones del mundo para el caso de maras la argentina se ha visto abocado al reconocimiento y protección por el Estado y las autoridades judiciales de este tipo de derechos.

En este estado es preciso plantear como interrogante ¿Cuál ha sido el desarrollo de la jurisprudencia de la Corte Suprema de la Nación Argentina para la protección de derechos colectivos? En las líneas posteriores se encontrará la génesis y desarrollo de los derechos colectivos por la Corte Suprema Argentina, que en sus inicios titubeo con la legitimación y solo hasta el año 1998 con el caso Halabi aclaró el tema y presento subreglas en la protección de los derechos colectivos., la trascendencia de la investigación de los pronunciamientos judiciales se funda en la inexistencia de normas claras que prevean el procedimiento para las pretensiones colectivas (Meroi, 2010,p.205).

La metodología utilizada es la explorativa, con un análisis pormenorizado de las decisiones judiciales, la unidad de análisis son los artículos constitucionales de protección de derechos colectivos y las variables, legitimación, alcance del amparo colectivo. Valiéndose de las fuentes primarias que reposan en la relatoría de la Corte como también de fuentes secundarias de los más destacados doctrinantes argentinos en el tema.

\section{La génesis}

Relata Salgado (2010) que la protección de derechos colectivos en Argentina inicia desde el caso de las toninas overas, sucedido en el año de 1983, mediante amparo se pretendía evitar la caza de 14 toninas, la pretensión se dirigió a la prohibición de cazar o pescar toninas overas en el mar hasta tanto existan estudios acabados acerca del impacto ambiental y faunístico que REVISTA VIA INVENIENDI ET IUDICANDI, Vol. 9, No. 1 
dicha caza pueda provocar, según consta en los anales de la Corte Suprema de la Nación (1983). La acción fue iniciada por Alberto E. Kattan y Juan Schroder contra el Estado nacional. Las consideraciones del fallo señalan el interés de los grupos ecologistas por la conservación de las especies, a su vez la desaparición de muchas especies por la mano del hombre, posteriormente considera la ley 2241 de protección a la fauna silvestre como la declaración de Estocolmo de 1972, como también en la ley 22.344 referida a la Convención sobre el Comercio Internacional de Especies Amenazadas de Fauna y Flora Silvestre, suscripta en Washington en 1973, con la participación de 88 Naciones, respondiendo a la recomendación 99 de la Conferencia de las Naciones Unidas de Estocolmo sobre Medio Ambiente Humano (1972).

Al tratar la legitimación, se parte del derecho subjetivo en cabeza de cada persona, pero realmente la protección al medio ambiente es un derecho subjetivo? La repuesta a este interrogante es que como tal son derechos cuyos titulares son cada una las personas que se consideren afectados y por tanto la afectación es predicable de todos pero no es una categoría de los derechos subjetivos. (1983). Finaliza el fallo no concediendo el amparo, pero anulando las resoluciones que conceden el permiso apoyada en la principio uira novit curia.

Para una mejor comprensión el tema investigado se acoge el criterio planteado por Verbi (2012) al dividir en cuatro etapas los derechos colectivos en Argentina; la primera inicia con el caso Toninas presentada en los párrafos anteriores la cual termina con la expedición de la constitución nacional y su artículo 43; etapa marcada por la discusión de derechos difusos apoyada en la ley fundamental. (Verbic, 2012, p.2)

\section{La legitimación en materia colectiva}

Con la reforma constitucional de 1994 se inicia la segunda etapa, sobresale el amparo iniciado por la senadora Cristina Zuccardi y la asociación de consumidores ("Prodelco"), entidad civil sin fines de lucro con domicilio en la Provincia de Mendoza, se pretende la inconstitucionalidad del art. $2^{\circ}$ del REVISTA VIA INVENIENDI ET IUDICANDI, Vol. 9, No. 1 
decreto 92 (1997) del Poder Ejecutivo Nacional -por el cual se aprobaron las modificaciones a la Estructura General de tarifas del Servicio Básico Telefónico, los argumentos de las pretensiones fueron: a) el art. $2^{\circ}$ del decreto 92 (1997) ("el artículo 2") sólo dispone "[...] rebajas para unos pocos clientes únicamente en materia de tarifas interurbanas e internacionales [...]"; y un "[...] aumento tarifario [...]" para la mayoría de los usuarios (fs. 18 vta., 19, último párrafo de fs. 12). Ello viola el art. 12.4.1 del Pliego de Bases y Condiciones para la Privatización del Servicio Telefónico que ordena rebajas anuales del 2\% -durante el período relevante en autos- en todas las tarifas de los servicios que presta Telefónica de Argentina S.A. ("la licenciataria"). Por esta razón el art. $2^{\circ}$ también infringe al art. 31 de la Constitución Nacional (fs. 12, 18 vta., 19 vta. y 21); b) "[...] la Secretaría de Comunicaciones de la Nación no presentó la propuesta [de rebalanceo de las tarifas telefónicas] que estaba obligada a someter a consideración de los asistentes [de la audiencia pública que precedió al dictado del artículo $2^{\circ}$ ]". Esta omisión de la demandada conculca la sentencia que había sido emitida in re "Adelco Liga Acción del Consumidor c/ Min. de E.O.S.P (Secretaría de Comunicaciones)" ("Adelco"). A raíz de que dicha sentencia se encuentra firme, el art. $2^{\circ}$ viola la garantía constitucional de la cosa juzgada (fs. $12 / 12$ vta.; 20/20 vta.); c) el artículo $2^{\circ}$ también viola el art. 10 de la Ley de Convertibilidad $N^{\circ} 23.928$, y, en consecuencia, el art. 31 de la Constitución Nacional (fs. 16). En primera instancia se accedió al amparo, en segunda instancia la Cámara de Apelaciones de Mendoza confirmo la decisión y ante esta se interpuso recurso extraordinario.

Los problemas jurídicos que estudio la Corte fueron dos por una parte la legitimación de la señora Zuccardi y/o Prodelco y por el otro la arbitrariedad o ilegalidad del decreto del Poder Ejecutivo Nacional № 92 (1997), para el caso de marras el carácter de ciudadano de la actora no es suficiente para denostar el interés concreto, inmediato y sustancial que permita considerar al pleito como una causa, caso o controversia, en los términos de los arts. 116 y 117 de la Constitución Nacional, único supuesto en que la mentada función puede ser ejercida (considerando $2^{\circ}$ del caso "Polino", Fallos: 317:335 (1994). 
Realiza la Corte un estudio de los antecedentes del decreto 92 (1997), afirma que es producto de actos administrativos que ostentan su presunción de legalidad, que mediante esa sucesión de actos administrativos se estableció un procedimiento para considerar el reajuste del cuadro tarifario del servicio telefónico, con amplia participación de los sectores interesados y la celebración de una audiencia pública destinada a la exposición de las más diversas opiniones sobre el punto a decidir. De otra parte, no le dado al poder judicial resolver controversias de tipo político su naturaleza radica en resolver causas y en el evento tarifario no se establece ninguna de ellas, cita para esto "Que todo lo expuesto lleva a la conclusión de que la petición de amparo se traduce en una mera disconformidad con la decisión política que se refleja en un aumento sectorial de tarifas en el servicio telefónico, cuestión que desde antiguo este Tribunal consideró ajena a su poder jurisdiccional. Corte Suprema de la Nación, consideración 22.

En relación con el amparo se afirma en el voto del señor ministro don Carlos S. Faty (1998) que la línea de precedentes donde señalan que la acción de amparo es un proceso excepcional, utilizable en las delicadas y extremas situaciones en las que por carencia de otras vías legales aptas peligra la salvaguarda de derechos fundamentales, y exige para su apertura circunstancias muy particulares caracterizadas por la presencia de arbitrariedad o ilegalidad manifiesta que, ante la ineficacia de los procedimientos ordinarios, originan un daño concreto y grave, sólo eventualmente reparable por esta vía urgente y expedita, su admisibilidad se produce cuando no media ilegalidad o arbitrariedad manifiesta, o cuando la determinación de la eventual invalidez del acto requiere mayor amplitud de debate y prueba ley 16.986 (1996), artículo 2 a su turno se estima la cosa juzgada produce efectos solamente respecto de quienes han revestido el carácter de partes en el juicio; es decir, dicha sentencia no puede aprovechar ni perjudicar a los terceros que han permanecido ajenos al juicio, por último se afirma que no hay cuestión justiciable porque "si se advierte que la supuesta lesión a los derechos de los consumidores que invocan las amparistas no sólo no es de carácter general, sino que la misma norma ha dado lugar a numerosas acciones judiciales algunas de las cuales actualmente se encuentran a conocimiento de este REVISTA VIA INVENIENDI ET IUDICANDI, Vol. 9, No. 1 
Tribunal- en las que se persigue el mantenimiento del nuevo régimen, por ser éste favorable a importantes sectores de habitantes del interior del país. (Corte Suprema de la Nación, 1998, p. 24)

La importancia de esta segunda etapa, radica en la discusión ya no sobre le interés subjetivo o simple como sucedía con su antecesora, sino en la legitimación de asociaciones para presentar en el proceso revaluando conceptos tradicionales de derecho procesal civil como la legitimación en la causa, se presenta una nueva postura procesal, la nueva interpretación que se adapta a la nueva categoría de derechos los colectivos ${ }^{2}$ : La normatividad puso su cuota al expedir la ley 25675 (2002) conocida como la ley general del ambiente, que en el artículo 35 consagra la legitimación ${ }^{3}$ en procesos colectivos y los efectos de la cosa juzgada ${ }^{4}$

Para la causa de los comprobantes fiscales, la Cámara de Comercio, Industria y Producción de Resistencia interpuso acción de amparo contra el Estado Nacional (Administración Federal de Ingresos Públicos - AFIP -), con el fin de que se declare la inconstitucionalidad de las Resoluciones Generales Nos. 4104 (DGI) y 259 (AFIP), que consagran modificaciones a la expedición de facturas y documentos similares, basando el amparo en la vulneración de

\footnotetext{
${ }^{2}$ Periodo de grandes debates en torno a los derechos colectivos en particular (i) la noción "derechos de incidencia colectiva"; (ii) la legitimación colectiva de cada uno de los sujetos contemplados en el art. $43 \mathrm{CN}$; (iii) el alcance subjetivo de la cosa juzgada; y (iv) la vía procesal por medio de la cual debían canalizarse este tipo de pretensiones. Luego, el debate se centró más específicamente en la posibilidad de tutelar situaciones que no involucraban un objeto mediato indivisible-como podría ser la recomposición del medio ambiente- sino situaciones pluriindividuales homogéneas

${ }^{3}$ Para una mayor compresión se trascribe el artículo 30. - Producido el daño ambiental colectivo, tendrán legitimación para obtener la recomposición del ambiente dañado, el afectado, el Defensor del Pueblo y las asociaciones no gubernamentales de defensa ambiental, conforme lo prevé el artículo 43 de la Constitución Nacional, y el Estado nacional, provincial o municipal; asimismo, quedará legitimado para la acción de recomposición o de indemnización pertinente, la persona directamente damnificada por el hecho dañoso acaecido en su jurisdicción.
}

Deducida demanda de daño ambiental colectivo por alguno de los titulares señalados, no podrán interponerla los restantes, lo que no obsta a su derecho a intervenir como terceros.

Sin perjuicio de lo indicado precedentemente toda persona podrá solicitar, mediante acción de amparo, la cesación de actividades generadoras de daño ambiental colectivo.

${ }^{4}$ Los efectos de cosa juzgada para este tipo de procesos se encuentran los regulados por el artículo 33, la sentencia hará cosa juzgada y tendrá efecto erga omnes, a excepción de que la acción sea rechazada, aunque sea parcialmente, por cuestiones probatoria 
derechos a la propiedad y el ejercicio de la industria licita de sus afiliados, el Juez Federal de Resistencia estimó que la vía del amparo es el medio judicial más idóneo para resolver sobre la materialidad del derecho que se denuncia conculcado. El Fisco Nacional interpuso el recurso extraordinario que fue concedido.

Estima la Corte que las facultades de reglamentación que confiere el art. 99 , inc. $2^{\circ}$, de la Constitución Nacional -art. 86 , inc. $2^{\circ}$, antes de la reforma de 1994-, habilitan para establecer condiciones o requisitos, limitaciones o distinciones que, aun cuando no hayan sido contemplados por el Legislador de una manera expresa, cuando se ajustan al espíritu de la norma reglamentada o sirven, razonablemente, a la finalidad esencial que ella persigue. Por otra parte, las alegaciones base de la vulneración del derecho al trabajo como la de capacidad económica de sus representados, carecen de elementos probatorios concretos, no existiendo demostración del perjuicio, del daño económico denunciado, ni de la situación financiera concreta de sus asociados ni de la imposibilidad efectiva de adquirir los equipos requeridos alguno sobre tales extremos, razón por la cual resultan -en la mejor de las hipótesis- agravios meramente conjeturales., por lo cual no se concederá el amparo solicitado. Corte Suprema de la Nación (2002)

\section{La norma ambiental y protección colectiva}

Con los daños derivados de la contaminación ambiental el Rio Matanza, comienza la tercera etapa con la acción promovida por Beatriz Silvia Mendoza y 16 personas más en representación propias ay de sus menores hijos otros actores, todos con domicilio en la Capital Federal y en la Provincia de Buenos Aires, interponen demanda contra el Estado Nacional poder ejecutivo nacional, contra la Provincia de Buenos Aires, contra el Gobierno de la Ciudad de Buenos Aires y contra cuarenta y cuatro empresas que desarrollan su actividad industrial en las adyacencias de la Cuenca (2006). Se funda las pretensiones en el incumplimiento de la normatividad ambiental y en los desechos peligrosos arrojados por las fábricas al rio., se pretende el cese de la contaminación y recomposición del medio ambiente. (2004) 
Muestra Álvarez Como medidas cautelares decretaron la creación de un fondo público para reparar las víctimas, la atención en salud a la población ribereña, reanudación y finalización del plan de gestión ambiental y la inscripción de la acción en los libros de comercio y en los libros de los accionistas de las empresas demandadas

Considera el juzgador la distinción de dos causas en la actuación judicial la primera tendiente a reparar daños individuales y la segunda bien de incidencia colectiva $^{5}$ por el daño futuro que se pretende mitigar, esto último fundado en el artículo 41 de la carta, en la parte dogmática que consagra los nuevos derechos y garantías y la correspondiente obligación de recomponer el daño ambiental $^{6}$ (2008)

Para concluir la tercera etapa se cita el caso verbistsky (2001), la causa se promovió por Horacio Verbitsky, representante legal del centro de estudios legales y sociales CELS interpuso habeas corpus preventivo y correctiva para proteger los derechos de las personas privadas de la libertad quienes se encontraban en condiciones que atenta su dignidad, en las 340 comisarías de Buenos Aires, es conocido en la doctrina argentina como apología del crimen, el periodista Horacio Verbitsky. requirió al tribunal de casación penal de

\footnotetext{
${ }^{5}$ La primera reclamación se refiere al resarcimiento de la lesión de bienes individuales, cuyos legitimados activos son las personas que se detallan en el considerando primero, y que reclaman por el resarcimiento de los daños a las personas y al patrimonio que sufren como consecuencia indirecta de la agresión al ambiente (punto 6. fs. 56 vta./75). la segunda pretensión tiene por objeto la defensa del bien de incidencia colectiva, configurado por el ambiente (fs. 75/76). En este supuesto los actores reclaman como legitimados extraordinarios (Constitución Nacional, Artículos 41, 43, y 30 de la Ley $\mathrm{N}^{\mathbf{0}} 25.675$ ) para la tutela de un bien colectivo, el que por su naturaleza jurídica, es de uso común, indivisible y está tutelado de una manera no disponible por las partes, ya que primero corresponde la prevención, luego la recomposición y, en ausencia de toda posibilidad, se dará lugar al resarcimiento (Artículo 28, ley citada).

${ }^{6}$ El reconocimiento de status constitucional del derecho al goce de un ambiente sano, así como la expresa y típica previsión atinente a la obligación de recomponer el daño ambiental no configuran una mera expresión de buenos y deseables propósitos para las generaciones del porvenir, supeditados en su eficacia a una potestad discrecional de los poderes públicos, federales o provinciales, sino la precisa y positiva decisión del constituyente de 1994 de enumerar y jerarquizar con rango supremo a un derecho preexistente, que frente a la supremacía establecida en el art. 31 de la Constitución Nacional y las competencias regladas en el art. 116 de esta Ley Fundamental para la jurisdicción federal, sostienen la intervención de este fuero de naturaleza excepcional para los asuntos en que la afectación se extienda más allá de uno de los estados federados y se persiga la tutela que prevé la Carta Magna.
} 
Buenos Aires la declaratoria de inconstitucionalidad e ilegalidad del encierro una vez verificará los supuestos referidos.

El tribunal considero entre otros aspectos que la vía no era la adecuada al existir diferencias entre las relaciones individuales y que como tal no era posible tramitarla como acción colectiva, por consiguiente la Sala III de la Cámara de Casación Penal de la Provincia de Buenos Aires decidió rechazar in limine la acción incoada al considerar que no era el órgano competente para intervenir en los hechos denunciados en la presentación sobre la base de que su competencia estaba limitada al conocimiento del recurso de la especialidad y al no ser posible tomar decisiones sobre situaciones plurales indeterminadas, a su vez que el habeas corpus debía tramitarse de manera individual en cada uno de los jueces donde estuviesen los detenidos.

Los accionantes presentaron recurso de nulidad e inaplicabilidad de ley ante la Suprema Corte de la Provincia de Buenos Aires (2005) en razón a la vulneración del artículo 43 constitucional, al desconocimiento de los precedentes entre otros aspectos; se destaca por el recurrente que es un error del tribunal considerar que el habeas corpus interpuesto debía ser presentado ante el juez de la causa por cada uno de los detenidos, el error se presenta en considerar que la acción colectiva es una suma de acciones individuales, lo que vulnera el artículo 43 de la Constitución que otorga legitimación a las organizaciones para accionar en forma colectiva, no obstante este recurso tampoco obtuvo éxito. Contra este pronunciamiento del tribunal superior local, la actora interpuso recurso extraordinario Federal, nuevamente denegado y ante lo cual deciden presentar Queja en su estudio el numeral 16 hace mención al artículo 43 y al amparo para el habeas corpus colectivo afirmando que este no se encuentra de manera expresa en el artículo constitucional, sin embargo por la categoría de los derechos vulnerados y su carácter de prioritario es posible. ${ }^{7}$

\footnotetext{
${ }^{7}$ Derecho infringido, la defensa de derechos de incidencia colectiva puede tener lugar más allá del nomen juris específico de la acción intentada, conforme lo sostenido reiteradamente por esta Corte en materia e interpretación jurídica, en el sentido que debe tenerse en cuenta, además de la letra de la norma, la finalidad perseguida y la dinámica de esa finalidad. 
La decisión adoptada fue declarar la procedencia de la queja, del recurso extraordinario y revocar la sentencia impugnada admitiendo el habeas corpus colectivo , citando entre sus consideraciones el art.1.1 de la Convención Americana sobre Derechos Humanos establece la obligación general de los Estados Partes, de respetar los derechos y libertades en ella consagrados y el pleno ejercicio a toda persona que está sujeta a su jurisdicción, lo que implica el deber de adoptar las medidas de seguridad necesarias para su protección. Estas obligaciones se tornan aún más evidentes en relación con las personas privadas de su libertad que están bajo custodia estatal. (Corte Suprema de la Nación, p.101)

En materia de protección ambiental, se promulgo la ley General del Ambiente $\mathrm{N}^{\circ} 25.675$ (2002), que consagra en su artículo 30 y siguientes la noción de daño ambiental colectivo, el acceso a la jurisdicción, los dictámenes, el alcance de la cosa juzgada y sus efectos erga onmes. En el ámbito judicial la Corte reguló lo concerniente al amicus $\mathrm{Curie}^{8}$, en todos los procesos judiciales correspondientes a la competencia originaria o apelada en los que se debatan cuestiones de trascendencia colectiva o interés general según Acordada No. 28 (2004), acordada 14 (2006), dejadas sin efecto por la acordada 7 (2013).

En similar sentido nueve años atrás, la ley 24.240 (1993) de defensa al consumidor da claridad frente a la legitimación para accionar otorgándose al consumidor, a las asociaciones de consumidores, y al ministerio público, la legitimación procesal.

En este estado de la investigación, es de vital importancia recordar que en el régimen jurídico de estado federal se otorga la posibilidad de las provincias de otorgarse su propia constitución, es el caso de la provincia de

\footnotetext{
${ }^{8}$ Las personas físicas o jurídicas que no fueran parte en el pleito, pueden presentarse ante la Corte Suprema de Justicia de la Nación en calidad de Amigo del Tribunal, en todos los procesos judiciales correspondientes a la competencia originaria o apelada, en los que se debatan cuestiones de trascendencia colectiva o interés general. La presentación deberá ser realizada con la única finalidad de expresar una opinión fundada sobre el objeto del litigio, dentro de los quince días hábiles del llamado de autos para sentencia. En la presentación deberá constituirse domicilio en los términos del art. 40 del Código Procesal Civil y Comercial de la Nación., artículo 1 
Córdoba que en su artículo 23 garantiza la protección de los intereses difusos, protección a cargo del defensor del pueblo por mandato constitucional del artículo 124., como ocurre a nivel federal según lo establece la norma fundamental.

\section{Halabi: La consolidación de los amparos colectivos}

Para la última etapa, nuevamente se acude a la acción de amparo por la inconstitucionalidad de la ley 25.873 (2004) y de su decreto reglamentario 1563 (2004), promovido por el abogado Ernesto Halabi fundado en la vulneración de las garantías constitucionales del artículo 18 y 19 que tratan del derecho la privacidad e intimidad. La mencionada normatividad autoriza la intervención de comunicaciones telefónicas y de internet, sin indicar en qué casos y bajo que justificación, para el efecto se declaró la inconstitucionalidad por la magistrada de primera instancia la cual fue confirmada por la sala II de la Camara Federal de Apelaciones en lo contencioso administrativo federal, ante esta decisión el Estado Nacional presenta recurso extraordinario federal, invocando invoca la existencia de cuestión federal, arbitrariedad y gravedad institucional, los argumentos expuesto se funda en " la impugnación del Estado Nacional se dirige exclusivamente a descalificar el efecto erga omnes que la cámara atribuyó a su pronunciamiento.

Al respecto señala que, sin perjuicio de la indudable dimensión colectiva de los derechos debatidos en el caso, según las prescripciones constitucionales, para conferir tal alcance al fallo era necesario la participación del defensor del pueblo de la nación en el proceso, circunstancia que no se ha producido.

Contiene el fallo Halabi, un pronunciamiento particular sobre la legitimación procesal y la distinción de derechos individuales, de incidencia colectiva que tiene por objeto bienes colectivos y de incidencia colectiva con objeto intereses individuales homogéneos. Para los eventos de lesión de bines jurídicos individuales la legitimación es del titular del derecho sin considerar que otras personas también sean afectados, se tratara e ese caso de REVISTA VIA INVENIENDI ET IUDICANDI, Vol. 9, No. 1 
pluralidad de partes o litisconsortes y le corresponde al titular probar la lesión y por tanto que su causa es justiciable, posteriormente expone la naturaleza del artículo 43 para derechos divisibles no homogéneos que pretende la reparación de un daño individual por el contrario los derechos de incidencia colectiva protegen bienes colectivos, correspondiendo su legitimación al defensor del pueblo, a las asociaciones que representan el interés colectivo y al afectado, es vital comprender que los bienes de incidencia colectiva pertenecen a la esfera social y no son indivisibles, es equivocado señalar que su legitimación corresponde a una pluralidad indeterminadas de personas, a la comunidad, no; son bienes que pertenecen a la sociedad.

Por otra parte, el artículo 43 constitucional trata también de los derechos de incidencia colectiva individuales homogéneo, a esta categoría corresponde los derechos patrimoniales que se derivan de la contaminación ambiental, los derechos de usuarios y consumidores entre otros. Los derechos son divisibles pero la causa de la lesión es homogénea razón por la cual es posible un solo proceso con extensión de la cosa juzgada. Corte Suprema de la Nación

Se presenta en el derecho argentino como lo expone el fallo una omisión del legislador al regular el tema de la acción colectiva, sin embargo el fallo establece los requisitos para su estudio: 1. Hecho único que causa la lesión a una pluralidad, 2. Pretensión apoyada en la homogeneidad, afectación de un numero plural por una misma circunstancia. 3. Que no sea posible demandar por el interés individual, porque la protección es para la sociedad. Volviendo a la falta de normativas consagra la Corte como las garantías constitucionales deben operar en favor de los administrados labor que le corresponde al juez en una interpretación de las cláusulas constitucionales conforme a la realidad social, comenta los antecedentes legislativos de las acciones de clase en el derecho anglosajón donde es posible distinguir tres tipos de acciones ${ }^{9}$. Llama la atención que los argumentos expuestos fueron esbozados por el doctor Ricardo Luis Lorenzetti en el salvamento de la acción de amparo ministerio de salud/gobernación en el año de 1996 y adoptados tres años después en el 
caso Halabi constituyéndose en la piedra angular de las acciones colectiva en Argentina.

Reitera la Corte que al no existir una reglamentación es necesario establecer un mínimo de requisitos y con ello proteger a su vez el derecho a la defensa en juicio, por lo tanto para la admisión de la acción colectiva se debe verificar la precisa identificación del grupo o colectivo afectado, la idoneidad de quien pretenda asumir su representación y la existencia de un planteo que involucre, por sobre los aspectos individuales cuestiones de hecho y de derecho que sean comunes y homogéneas a todo el colectivo, también la debía notificación a quienes tenga interés y la publicidad para evitar interponer procesos con idéntico objeto.

En el tema de los efectos de la cosa juzgada, se apoya en el carácter de la acción colectiva en su raigambre constitucional y la normatividad especial como es el caso de la ley de los consumidores y el daño ambiental.

Para el caso de marras la Corte confirma el fallo citando para ello normas internaciones y precedentes del derecho español que protegen el derecho a libertad e intimidad, se presenta la disidencia de la doctora Highton de Nolasco deja a salvo su opinión respecto a la legitimación del Defensor del Pueblo de la Nación para la defensa de intereses individuales homogéneos puramente patrimoniales.

Conoce la Corte Suprema de la Nación en acción de amparo de Cavalieri Jorge y Otro /c Swiss Medical S.A. de fecha 26/06/2012, presentado por la asociación de consumidores contra una empresa de medicina prepaga, con el objeto de que provea de equipos de ventilación mecánica y accesorios para el tratamiento del "síndrome de apnea obstructiva severa" a todos sus afiliados que padezcan dicha enfermedad y requieran tratamiento. La Corte se abstuvo de aplicar la teoría expuesta en Halabi para la legitimación, recordó los requisitos la procedencia de este tipo de acciones requiere la verificación de una causa fáctica común, una pretensión procesal enfocada en el aspecto colectivo de los efectos de ese hecho y la constataci6n de que el ejercicio REVISTA VIA INVENIENDI ET IUDICANDI, Vol. 9, No. 1 
individual no aparece plenamente justificado. El primer elemento es la existencia de un hecho único o complejo que causa una lesi6n a una pluralidad relevante de derechos individuales. El segundo elemento consiste en que la pretensión debe estar concentrada en los efectos comunes y no en lo que cada individuo puede peticionar, como ocurre en los casos en que hay hechos que dañan a dos o más personas y que pueden motivar acciones de la primera categoría. Como tercer elemento es exigible que el interés individual considerado aisladamente, no justifique la promoción de una demanda, con lo cual podría verse afectado el acceso a la justicia. Manifestó también que no se había demostrado por parte de la asociación el interés homogéneo propio de las acciones colectivas.

Para el año 2013 la fundación ambiente y desarrollo FUNDAYD y la fundación Centro de Derechos Humanos y ambiente CEHDA, formulan demanda con la pretensión de amparo al daño ambiental contra el Estado de las provincias de Tucumán y Santiago del Estero, y las treinta y tres empresas para que se ordene cesar la contaminación de la cuenca del rio Sali-dulce; las fundaciones señaladas se encuentran legitimadas conforme al artículo 43, se analiza en el fallo el cumplimiento del artículo 30 de la ley 25.675 en el tema de la petición de daños por otros afectados con anterioridad la presentación de la demanda otorgando a quienes posteriormente los soliciten la posibilidad de actuar como terceros y para el caso la provincia de Santiago del Estero y el defensor del pueblo ya habían promovido acción con objeto idéntico, por esta razón no se dio curso a la acción ${ }^{10}$

Posteriormente solicitando la nulidad de las cláusulas contractuales la asociación "Prevención, Asesoramiento y Defensa del Consumidor" PADEC, interpuso demanda contra Swiss Medical S.A. con el objeto de que se declarara la ineficacia de las cláusulas contenidas en el contrato tipo que vincula a la empresa con sus afiliados, en cuanto contemplan el derecho de aquélla a modificar unilateralmente la las cuotas mensuales y los beneficios de los planes que ofrece, la exime de responsabilidad por daños y perjuicios

\footnotetext{
${ }^{10} \mathrm{http}$ //www.csjn.gov.ar/confal/ConsultaCompletaFallos.do?method=verDocumentos\&id=704414 REVISTA VIA INVENIENDI ET IUDICANDI, Vol. 9, No. 1 UNIVERSIDAD SANTO TOMÁS, BOGOTÁ ISSN 1909-0528
} 
derivados de la impericia, culpa, dolo, imprudencia o negligencia de sus prestadores y la responsabilidad por la suspensión del servicio" nuevamente e se expone el precedente Halabi los requisitos y la legitimación en derechos colectivos, comprobando que los derechos que se buscan proteger ostentan la categoría de intereses individuales homogéneos, en consideración al derecho de la empresa demanda de modificar unilateralmente las cuotas de medicina prepagada propiciando un daño a un número plural de personas lo que configura el hecho único el segundo requisito son los efectos comunes para las personas afectadas, finalmente la legitimación de no aceptarla se vulneraría el acceso a la justicia.

En igual sentido del caso anterior, el 14 de marzo de los corrientes se conoce del recurso de apelación formulado por la unión de usuarios y consumidores contra telefónica comunicaciones personales S.A, la pretensión se dirigió en obtener la cesación de la imposición de pagos (tasa de fiscalización y aportes) a su vez la devolución de las sumas cobradas desde el año de 2001, considero la sala III de apelaciones que la asociación no estaba legitimada, situación que fue rechazada en el recurso federal donde se consideró que le asiste pleno interés conforme al artículo 43, y por existir un hecho único susceptible de ocasionar una lesión a los derechos de una pluralidad de sujetos- imposición de tasa y aporte- a los usuarios y la pretensión de la recurrente está concentrada en los "efectos comunes" para toda la clase de los sujetos afectados, en tanto la conducta cuestionada afectaría por igual a todos los usuarios del servicio de telefonía móvil prestado por la demandada. Corte Suprema de la Nación (2014). Es similar el caso estudiado al fallo el día 21 de agosto de 2013 en la causa, PADEC c/ Swiss Medical S.A. s/ citando la acción sumarísima usuarios y consumidores contra telefónica argentina S.A. Corte Suprema de la Nación (2014).

Efectuado el corrido por los fallos de la Corte Suprema de la Nación de mayor transcendencia que han constituido precedentes en derechos de incidencia colectiva, se aprecia la evolución en la tutela judicial colectiva en Argentina, estos derechos sujetos de la acción de amparo regulada por la ley 13928, (2008) modificada por la ley 14.192 (2010), normas que regulan entre 
otros los requisitos de la demanda ${ }^{11}$ en seis numerales no difieren de otras demanda que protejan derechos individuales, por su parte el artículo $7^{12}$ impone como requisito además de los referidos la indicación de los efectos comunes y del hecho único que causa la lesión., la inscripción de la demanda en el registro de amparos de incidencia colectiva que tiene por objeto conocer la existencia de otras acciones con carácter similar y si es del caso remitir al juez competente.

Por último y de gran actualidad, cabe destacar el establecimiento y la vigencia del registro de procesos colectivos, creado por el artículo 21 de la ley de amparo (2010), quedando subsumido en él los amparos de incidencia colectiva en razón a la trascendencia social según lo establecido por la Corte Suprema de la Nación, según Acordada ${ }^{13} 3660$ (2013), se instaura el registro, el trámite, las obligaciones, la publicidad, el suministro y manejo de la información serán los señalados en el anexo de la acordada, divide los procesos en cuatro a saber: amparos de incidencia colectiva Ley 13.928 (2008) y Ley 14.192 (2010); b) Amparos de incidencia colectiva tramitados en extraña

${ }^{11}$ Artículo $6^{\circ}$ : (Texto según Ley 14192) La demanda deberá interponerse por escrito y contendrá:

1) Nombre, apellido, razón o denominación social, domicilio real y constituido del accionante.

2) La justificación de la personería invocada conforme las leyes en vigor.

3) La individualización en lo posible, del autor del acto u omisión.

4) La relación circunstanciada de los hechos, actos u omisiones que hayan producido o estén en vías de producir la lesión del derecho o garantía cuyo amparo se pretende.

5) Ofrecimiento de toda prueba de la que intente valerse, adjuntando la que obrare en su poder.

6) La petición, en términos claros y precisos.

Será admisible todo tipo de prueba que no se contraponga con los principios de celeridad y economía procesal.

12 Artículo $7^{\circ}$ : (Texto según Ley 14192) En el caso de amparos de incidencia colectiva, la demanda tendrá que contener, además de lo establecido en el artículo anterior, la referencia específica de sus efectos comunes.

Respecto de los procesos sobre intereses individuales homogéneos, la pretensión deberá además de concentrarse en los efectos comunes, identificar un hecho único o complejo que cause la lesión; el interés individual no debe justificar la promoción de demandas individuales, y debe garantizarse una adecuada representación de todas las personas involucradas.

La representación adecuada del grupo resulta de la precisa identificación del mismo, la idoneidad de quien pretenda asumir su representación, la debida notificación y publicidad del litigio y el planteo de cuestiones de hecho y de derecho comunes y homogéneas a todo el colectivo.

${ }^{13}$ Resolución de carácter administrativo y general que dictan las cortes y tribunales supremos de justicia en uso de sus facultades de superintendencia y dentro de los límites de su jurisdicción, para regular sus propias actividades y las de todos los organismos judiciales que de ellos dependen 
jurisdicción; c) Otros procesos de incidencia colectiva radicados en la provincia; d) Otros procesos de incidencia colectiva tramitados en otras jurisdicciones.

\section{Referencias bibliográficas}

CHAUMET, Mario (__ $)$, Las esculas judiciales en la posmodernidad, documento recuperado el 10.09.2014, de http://www.cartapacio.edu.ar/ojs/index.php/centro/article/viewFile/566/474

CHAUMET, Mario (__ ), Reflexiones sobre la implementación de ka decisión judicial complea: el caso de los intereses supraindividuales, documento recuperado el 10.09.2014, de http://www.aafd.org.ar/archivos/17 jornada Chaumet.pdf

Corte Suprema de Justicia de la Nación (2013), fallo Fundación Ambiente y Desarrollo y Fundación Centro de Derechos humanos y Ambiente v. Provincia de Tucumán y otros (daño ambiental), Buenos Aires, Argentina, documento recuperado el 10.09.2014, de http://www.csjn.gov.ar/confal/ConsultaCompletaFallos.do?method=verDocume $\underline{\text { ntos\&id }=704414}$

Corte Suprema de Justicia de la Nación, fallo PADEC v. Swiss Medical S. A. (nulidad cláusulas contracutales), Buenos Aires, Argentina, documento recuperado el 10.09.2014, de http://www.csjn.gov.ar/confal/ConsultaCompletaFallos.do?method=verDocume $\underline{\text { ntos\&id }=703483}$

Corte Suprema de Justicia de la Nación, recurso de hecho Centro de Legales y Sociales v. Suprema Corte de Justicia de la provincia de Buenos Aires, Buenos Aires, Argentina, documento recuperado el 10.09.2014, de http://www.csjn.gov.ar/jurisp/jsp/fallos.do?usecase=mostrarHjFallos\&fallold=70 $\underline{648}$

http://www.jursoc.unlp.edu.ar/documentos/publicaciones/a 6 anios casoVerbit sky.pdf

Corte Suprema de Justicia de la Nación, fallo Unión de Usuarios y Consumidores v. Telefónica Comunicaciones Personales S. A., Buenos Aires, Argentina, documento recuperado el 10.09.2014, de http://www.infojus.gob.ar/jurisprudencia/FA14000016-union telefonica ampfederal-2014.htm;jsessionid=1 qfhdtn2i6ulm10t4thgvmz918?0

GALDÓS, Jorge Mario (2011), La causa "Halabi" de la Corte Suprema, en revista Jurídica del Centro, No. 1, documento recuperado el 10.09.2014, de http://www.cartapacio.edu.ar/ojs/index.php/RJC/article/view/1346/1531

LORENZETTI, R. (2010) Justicia Colectiva. , Buenos Aires. Rubinzal Culzoni.

MEROI, Andrea (2008). Procesos colectivos. Buenos Aires. Rubinzal Culzoni. 
MORELLO, Augusto. (2011) La tutela de los intereses difusos en el derecho argentino: legitimaciones, medidas cautelares, trámite y efectos del amparo colectivo. Argentina: Librería Editora Platense S.R.L.

Presidente de la Nación Argentina (1966), Ley 16.986, Ley de Acción de Amparo, en Boletín oficial del 20 de octubre de 1966, Buenos Aires, Argentina, documento recuperado el 10.09. 2014, de http://legales.com/tratados/p/pamparo.htm

Salgado. J. (2011) Tutela individual Homogénea. Buenos Aires. Astrea.

Salgado, J. (2010) Los derechos de incidencia colectiva en la jurisprudencia de la Corte Suprema de Justicia de la Nación. Buenos Aires, Rubinzal Culzoni.

Senado y Cámara de Diputados de la Provincia de Buenos Aires (2009), Ley 13.298, de la promoción y protección integral de los Derechos de los niños, Buenos Aires, Amparo Boletín Oficial $\mathrm{N}^{\circ} 26068$, documento recuperado el 10.09.2014, de http://www.gob.gba.gov.ar/legislacion/legislacion/l-13298.html

Senado y Cámara de Diputados de la Provincia de Buenos Aires (2010), Ley 14.192., Buenos Aires, Argentina, documento recuperado el 10.09.2014, de http://www.gob.gba.gov.ar/legislacion/legislacion/l-14192.html

VERBIC, Francisco. (2007), Procesos Colectivos. Buenos Aires, Astrea.

VERBIC, Francisco (2009), El proceso colectivo en la nueva ley de amparo de la Provincia de Buenos Aires: Falta de visión sistemática y un oportuno veto parcial del Poder Ejecutivo, documento recuperado el 10.09.2014, de http://www.academia.edu/3715653/El proceso colectivo en la nueva ley de amparo de la Provincia de Buenos Aires. Falta de vision sistemica y un oportuno veto del Poder Ejecutivo 